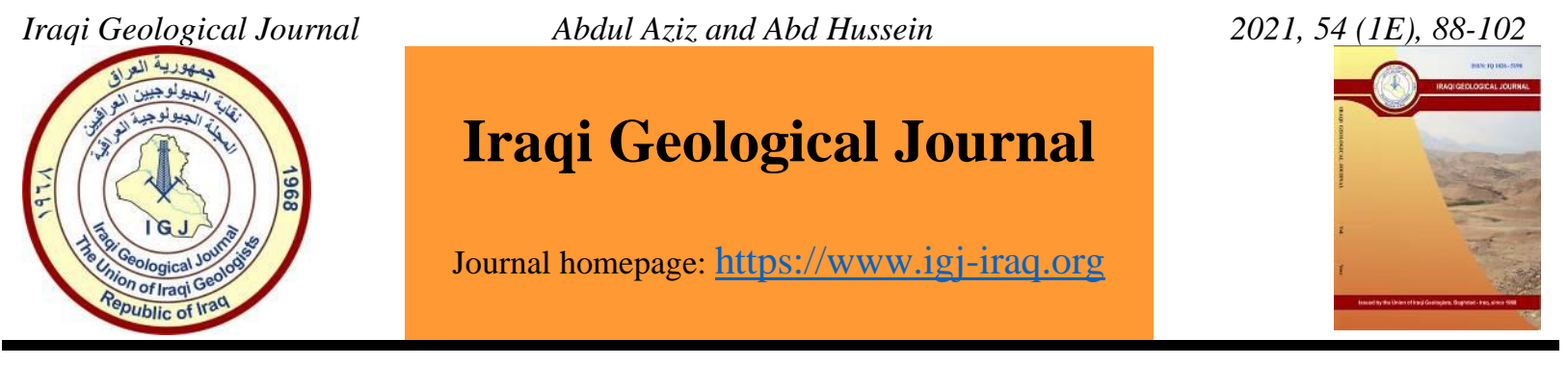

\title{
Mechanical Rock Properties Estimation for Carbonate Reservoir Using Laboratory Measurement: A Case Study from Jeribe, Khasib and Mishrif Formations in Fauqi Oil Field
}

\author{
Qahtan A. Abdul Aziz ${ }^{1, *}$ and Hassan A. Abdul Hussein ${ }^{1}$ \\ 1 Petroleum Engineering Department, College of Engineering, University of Baghdad \\ * Correspondence: Kahtanadnan72@yahoo.com
}

Received: 17 January 2021; Accepted: 6 April 2021; Published: 31 May 2021

\begin{abstract}
Estimation of mechanical and physical rock properties is an essential issue in applications related to reservoir geomechanics. Carbonate rocks have complex depositional environments and digenetic processes which alter the rock mechanical properties to varying degrees even at a small distance. This study has been conducted on seventeen core plug samples that have been taken from different formations of carbonate reservoirs in the Fauqi oil field (Jeribe, Khasib, and Mishrif formations). While the rock mechanical and petrophysical properties have been measured in the laboratory including the unconfined compressive strength, Young's modulus, bulk density, porosity, compressional and shear -waves, well logs have been used to do a comparison between the lab results and well logs measurements. The results of this study revealed that petrophysical properties are consistent indexes to determine the rock mechanical properties with high performance capacity. Different empirical correlations have been developed in this study to determine the rock mechanical properties using the multiple regression analysis. These correlations are UCS-porosity, UCS-bulk density, UCS-Vs, UCs-Vp Es-Vs, Es-Vp, and Vs-Vp. (*). For example, the UCS-Vs correlation gives a good determination coefficient $(\mathrm{R} 2=0.77)$ for limestone and $(\mathrm{R} 2=0.94)$ for dolomite. A comparison of the developed correlations with literature was also checked. This study presents a set of empirical correlations that can be used to determine and calibrate the rock mechanical properties when core samples are missing or incomplete.
\end{abstract}

Keywords: Petrophysical rock properties; Unconfined compressive strength, Shear P-wave velocity

\section{Introduction}

Rock mechanical properties are significant in establishing the plans associated with drilling, completion, stimulation, production, and reservoir monitoring processes (Meehan, 1994; Bjorlykke and Hoeg, 1997). When a piece of rock is subjected to sufficiently large stresses, some kinds of failures will occur. This implies that the rock shape will permanently change, and possibly fall apart. This condition is accompanied by reducing the ability to carry loads. Carbonate rocks are complex and thus rock mechanical properties are heterogenous (Tawfeeq and Al-Sudani, 2020). While rock mechanical laboratory testing is the most accurate method for calculating the rock strength (Rabbani et al., 2012). Core testing, unfortunately, can never lead to a continuous profile of rock strength along the wellbore.

DOI: 10.46717/igj.54.1E.8Ms-2021-05-29 
The coring is very expensive, and it is very sensitive to stress unloading. The number of core samples is also restricted due to time limitations as well as the availability of good quality core. Besides that, the lab results may not be fully representative of the entire reservoir section due to complex variations in rock composition (Rabbani et al. 2012). Rock failure is also an important phenomenon for petroleum related rock mechanics, as it is the origin of severe problems such as borehole instability and solids production. It is therefore useful to be able to predict under which conditions a rock is likely to fail (Raeen, et al. 1996; Rabbani et al. 2012). The unconfined compressive strength (UCS) is the essential parameter for planning the mud weight window, bit selection and wellbore stability analysis. Besides, it is very important for reservoir subsidence and reservoir acidizing studies. When using this parameter, it is important to choose the proper weight on bit, evaluate drilling operation efficiency, bit wear and efficient bit lifetime in use (Nabaei et al. 2010, Rabbani et al. 2012). Several authors have been established many empirical correlations to estimate the mechanical properties (Militzer and Stoll, 1973; Sharma and Singh, 2010; Karamia et al. 2012; Castagna et al. 1993; Ameen et al. 2009; Chamge, 2004; Smorodinovet, et al. 1970; Khandelwal and Singh, 2009; and Karamia et al. 2012. Hadi and Nyaagred, 2018; Abdulmajeed and Alhaleem, 2020). Table 1 lists these studies along with the equations of the rock mechanical and petrophysical properties. The prediction of mechanical properties using petrophysical properties is more reliable, especially in carbonates rocks.

Table 1: Empirical correlations to predict the mechanical rock properties from petrophysical properties in carbonate

\begin{tabular}{lc}
\hline Model & Empirical Correlation \\
\hline Militzer and stoll (1973) & $U C S=2.45 V P^{1.92}$ \\
Sharma and Singh (carbonate) (2010) & $U C S=36 V_{P}-45.37$ \\
Karamia et al. (2012) & $U C S=35.35 V_{s^{-}} 7.588$ \\
Castagna (limestone) (1993) & $V_{S}=0.4403 V_{P}+0.576$ \\
Castagna (dolomite) (1993) & $V_{S}=0.467_{P}+0.5895$ \\
Ameen et al. (carbonate rock) (2009) & $V_{s}=0.52 V_{P}+0.25251$ \\
Al-kattan (carbonate)(2015) & $V_{P}=0.699 V_{P}^{0.969}$ \\
Hadi and Nyaagred (carbonate rock) (2018) & $V s=0.1206+0.44104 V_{p}+0.1215 \rho b u l k$ \\
Abdul Majee and Alhaleem (carbonate) (2020) & $V s=0.52 V p+0,0562$ \\
Chamge (for carbonate rock) (2004) & $U C S=143.8 e^{-6.95 \varnothing}$ \\
Smorodinovet et al. (for carbonate rocks) (1970) & $U C S=0.88 e^{2.85 p}$ \\
Khandelwal and Singh (limestone) (2009) & $E_{S}=4.9718 V_{p}-7.151$ \\
Karamia et al(limestone)(2012) & $E_{S}=8.804 V_{S}+6.238$ \\
\hline
\end{tabular}

Most of these models are empirical correlations established based on geophysical well logs, such as acoustic porosities or velocities porosities, to determine laboratory-derived mechanical rock properties (Yagiz, 2011). These correlations are based on the fact that several same factors that affect mechanical rock properties also affect physical properties, such as porosity, velocity, and elastic moduli (Chang et al. 2006). Generally, the relationships of mechanical rock properties and physical rock properties established for specific formation depending on the calibration of laboratory tests on rock samples from a specified field. The aim of this study is to correlate the rock mechanical properties with petrophysical properties using experimental work of many core samples that have been taken from three formations which are Jeribe, Khasib and Mishrif formations. This study has been conducted in the production section of the Fauqi oil field (South East Iraq). A major issue of this field is that no local empirical correlations can be used to determine the rock mechanical properties in terms of petrophysical for many applications related to geomechanics. 


\section{Geological Setting of the Study Area}

Missan Oilfield is located in southeastern Iraq and close to the Iraq-Iran border. The field consists of three producing oilfields, namely Abu Ghirab, Buzurgan and Fauqi oilfields. Stru Fauqi oilfield has two sets of reservoirs, Tertiary Asmari and Cretaceous Mishrif. Three pay zones are divided in the Asmari reservoir which is A, B and C. The pay zone A of Asmari consists of mainly dolomite. The pay zone $\mathrm{B}$ is dolomite intercalated with sandstone, limestone and thin shale. The pay zone $\mathrm{C}$ is mainly the sandstone, intercalated with a few dolomite, mudstone and limestone. The main reservoir in the Fauqi oilfield is cretaceous Mishrif. Seven pay zones are divided in the Mishrif reservoir, which are MA, MB11, MB12, MB21, MB22, MC1 and MC2. More details about the studied formations are listed in Table.

Table 2. The geological description of the studied formations

\begin{tabular}{lccc}
\hline Formation Name & $\begin{array}{c}\text { Thickness } \\
(\mathbf{m})\end{array}$ & Lithology & $\begin{array}{c}\text { No. of } \\
\text { Core Samples }\end{array}$ \\
\hline \multirow{2}{*}{ Jeribe-Euphrates } & $2997.5-$ & dolomite intercalated with argillaceous dolomite, and & 4 \\
& 3046.07 & conglomerate and locally anhydrite argillaceous & 4 \\
Khasib & $3824.0-$ & limestone, with calcareous claystone on bottom. & 9 \\
& 3886.0 & & \\
Mishrif & $3886.0-$ & Limestone interbed with thin argillaceous limestone & \\
\hline
\end{tabular}

\section{Materials and Methods}

In this study, mechanical rock properties were determined using core samples collected from different reservoir intervals from different wells. Seventeen core samples of limestone and dolomite were obtained from Jeribe, Khasib and Mishrif formations in the FAUQI oil field. The length of studied cores is ranged from $2.3 \mathrm{~cm}$ to $4.43 \mathrm{~cm}$, while the width is ranged from $2.34 \mathrm{~cm}$ to $2.5 \mathrm{~cm}$.

\subsection{Uniaxial Compressive Strength (UCS) Test}

The uniaxial compressive strength, or UCS, test is a destructive technique for determining the uniaxial compressive strength of intact rock core specimens. In rock mechanics and engineering geology, the UCS test considered to be the most widely used methods to obtain rock strength properties. Uniaxial compressive strength values $(\sigma f)$ were calculated using the following simple formula:

$$
\sigma_{f}=\frac{F_{f}}{A}(1)
$$

where $\mathrm{Ff}$ is the force applied by the hydraulic cylinder to the sample at the time of catastrophic failure, $\mathrm{A}$ is the area of the ends of the sample, and is uniaxial compressive stress at failure that is equal to the UCS. Under the assumption that the material is isotropic one can also determine the Young's modulus E.

$$
E=\frac{\sigma}{\varepsilon_{\text {axial }}(2)}
$$

and Poisson's ratio $v$

$$
v=\frac{\varepsilon_{\text {radial }}}{\varepsilon_{\text {axial }}(3)}
$$

where $\varepsilon$ axial and $\varepsilon$ radial are provided by the strain gauges mounted parallel and perpendicular to the cylindrical sample's axis, respectively. The lab apparatus used in this study for measuring the UCS, is shown in Fig.1. The experiment started with putting the core sample between two plates contacted 
with the top platen. An axial load about $100 \mathrm{~N}$ is applied to core sample using the loading frame for fixing the core sample. The results are recorded with different axial forces until the core is crushed or fractured.

\subsection{Ultrasonic Test}

The velocity of propagation (Vp) and shear velocity (Vs) of core samples were measured with an ultrasonic device according to standard ASTM (1986) (Fig. 2). Measure the length or height of the specimen. Clean the upper and lower surfaces of the specimen and put little amount of any kind of grease on them to have complete adhesion between the specimen surfaces. put the specimen between the two transducers. Put the tester on to generate the pulse move the certain kind of P-waves and shear waves velocity could be obtained by using the two kinds of transducers each one specified fore wave shape on the oscilloscope to read out the arrival time of the wave the pointer must be the begin point of pulsation when recording the time. Measuring of primary waves velocity. The velocities of either $\mathrm{P}$ or $\mathrm{S}$ wave are calculated as follows:

$$
V p(\text { or } V s)=\frac{S}{t}
$$

where VP is the P-wave velocity $(\mathrm{km} / \mathrm{s})$, VS is the S-wave velocity $(\mathrm{km} / \mathrm{s}), \mathrm{S}$ is the distance traveled by the wave $(\mathrm{mm})$, and $\mathrm{t}$ is the travel time in this method, the wave frequency must be high, and the rock specimens must have infinite extent compared to the pulses' wavelength. This test is performed following the ISRM (2007). Fig. 3 shows several samples that were used before and after testing.

\section{Results and Discussions}

Table 3 represents experimental results of mechanical and physical rock properties for carbonate reservoir. Table 4 presents the JMP software's statistical output in terms of mean and standard deviation parameters for thirteen samples of limestones and four samples of dolomites for the involved properties.

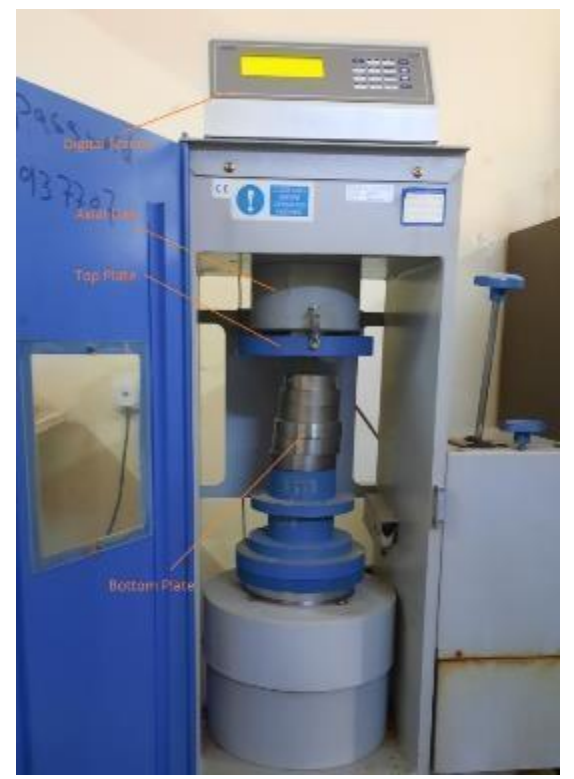

Fig. 1. Apparatus of uniaxial compressive test for measuring of UCS and Es 


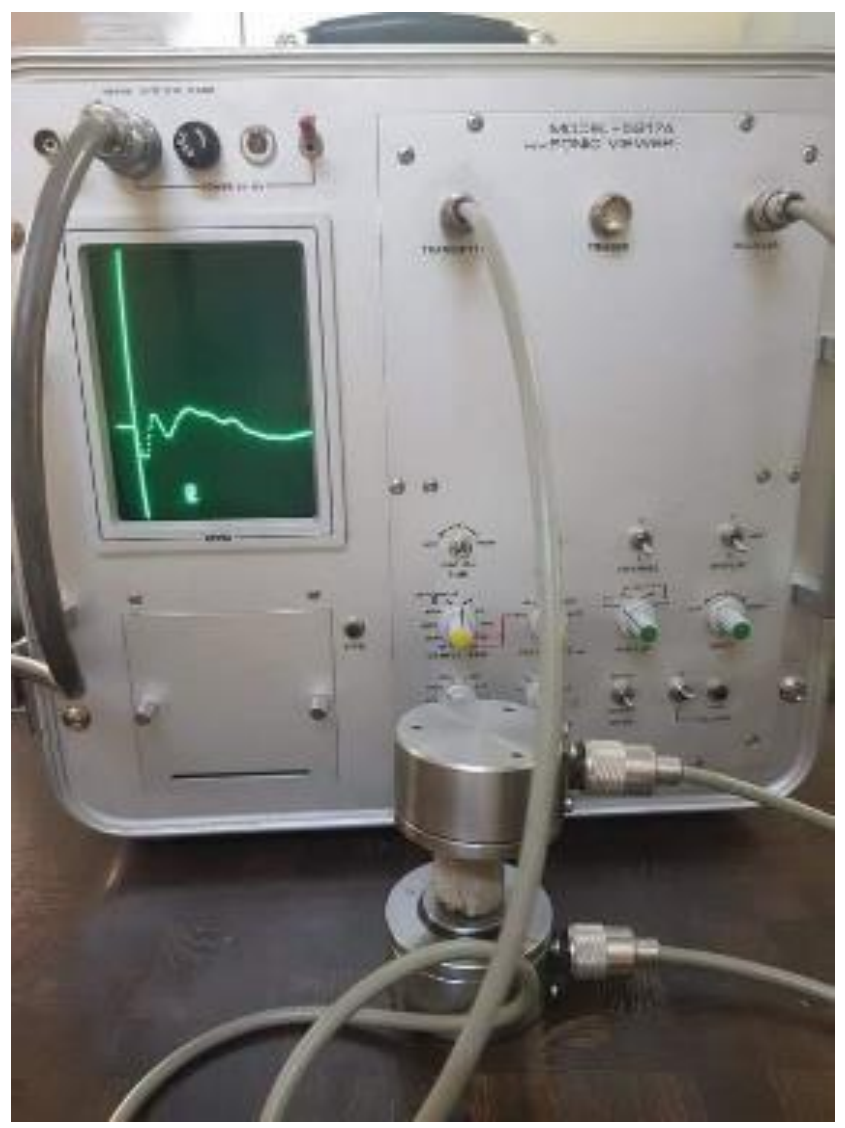

Fig. 2. Apparatus of ultrasonic testing for measuring of P-wave and S-wave

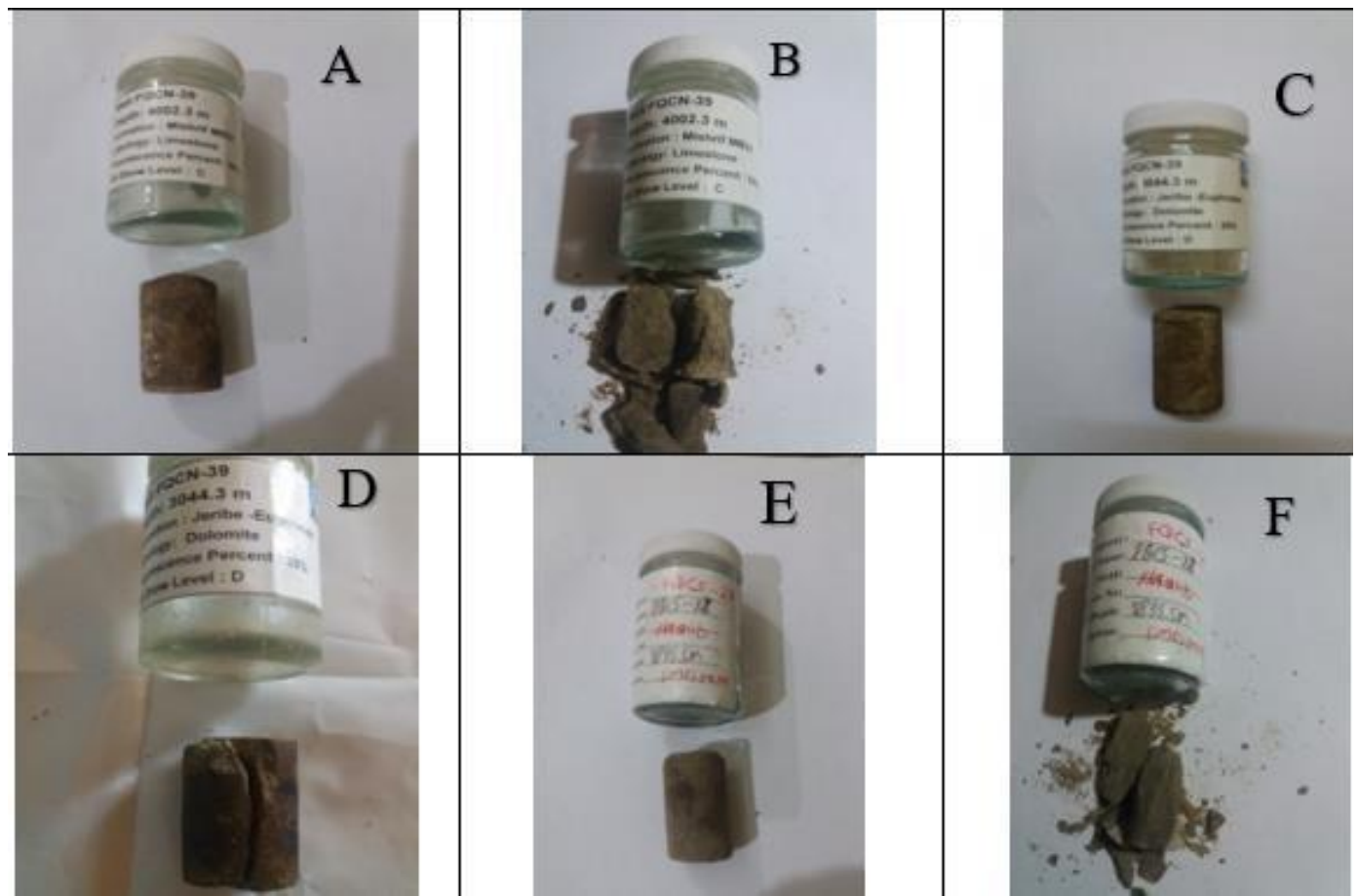

Fig.3: core samples before and after uniaxial tests (A \& B) for the Mishrif Formation, (C \& D) for the Jeribe Formation (E \& F) for the Khasib Formation 
Table 3. Experimental results of mechanical and physical rock properties for carbonate reservoir

\begin{tabular}{|c|c|c|c|c|c|c|c|c|}
\hline Depth & Lithology & Formation & $\begin{array}{l}\text { UCS } \\
\text { Мpa }\end{array}$ & $\begin{array}{c}\text { Vp } \\
\text { Km/Sec }\end{array}$ & $\begin{array}{c}\text { Vs } \\
\text { Km/Sec }\end{array}$ & $\begin{array}{c}\text { Bulk } \\
\text { density }\end{array}$ & Es & Porosity \\
\hline 3044 & Dolomite & Jeribe & 8.35 & 3.7 & 1.85 & 2.483 & 22.661 & 10.359 \\
\hline 3022 & Dolomite & Jeribe & 5.095 & 2.25 & 1.285 & 2.305 & 9.571 & 12.863 \\
\hline 3027 & Dolomite & Jeribe & 6.805 & 3.316 & 1.913 & 2.356 & 21.564 & 15.161 \\
\hline 3945 & Limestone & Mishrif & 11.633 & 4.259 & 2.407 & 2.484 & 36.42 & 9.5 \\
\hline 3814 & Limestone & Khasib & 12.12 & 3.916 & 2.232 & 2.433 & 30.529 & 11.019 \\
\hline 3867 & Limestone & Khasib & 10.395 & 2.75 & 1.627 & 2.386 & 15.546 & 9 \\
\hline 4035 & Limestone & Mishrif & 10.2 & 2.95 & 1.85 & 2.461 & 19.8 & 8.435 \\
\hline 2988 & Dolomite & Jeribe & 12.427 & 4.387 & 2.835 & 2.75 & 50.458 & 3.47 \\
\hline 4040 & Limestone & Mishrif & 4.2 & 2.85 & 1.61 & 2.206 & 14.47 & 15.02 \\
\hline 3929 & Limestone & Mishrif & 14.1 & 5.25 & 3.04 & 2.65 & 61.12 & 6.2 \\
\hline 4086 & Limestone & Mishrif & 10.04 & 3.52 & 2.2 & 2.38 & 27.17 & 9.8 \\
\hline 3876 & Limestone & Mishrif & 16.12 & 4.85 & 3.47 & 2.7 & 63.43 & 5.7 \\
\hline 3837 & Limestone & Khasib & 11.88 & 4.56 & 2.58 & 2.45 & 41.24 & 9.2 \\
\hline 4102 & Limestone & Mishrif & 11.49 & 4.15 & 2.5 & 2.37 & 36 & 10.21 \\
\hline 3835.5 & Limestone & Khasib & 12.8 & 5 & 2.77 & 2.66 & 52.19 & 9.8 \\
\hline 4153 & Limestone & Mishrif & 15.21 & 5.76 & 3.27 & 2.78 & 64.24 & 4.3 \\
\hline 4002 & Limestone & Mishrif & 11.99 & 4.61 & 2.6 & 2.53 & 43.33 & 10.32 \\
\hline
\end{tabular}

Table 4. Summary of statistical data obtained from laboratory tests.

\begin{tabular}{lcccc}
\hline Parameter & \multicolumn{2}{c}{ Limestone } & \multicolumn{2}{c}{ Dolomite (4 samples) } \\
\hline & Mean & St. Dev & Mean & St. Dev \\
UCS $(\mathrm{Mpa})$ & 12.37 & 2.35 & 9.07 & 2.863 \\
Vp $(\mathrm{Km} / \mathrm{s})$ & 4.38 & 0.877 & 3.588 & 0.755 \\
Vs $(\mathrm{Km} / \mathrm{s})$ & 2.599 & 0.557 & 2.127 & 0.610 \\
Bulk density & 2.508 & 0.156 & 2.485 & 0.1 \\
Es & 46.14 & 15.685 & 34.6 & 15 \\
Porosity & 9.84 & 2.546 & 12 & 3.27 \\
\hline
\end{tabular}

In the following sections, correlation between individual mechanical and physical properties will be presented separately as follows:

\subsection{Correlation between Mechanical and Petrophysical Properties}

\subsubsection{Correlation between USC and S-wave Velocity}

Fig. 4 shows the laboratory measured ultrasonic S-wave velocity (Vs) along with UCS results for limestone and dolomite samples. Two relationships between UCS and Vs have been presented where UCS in MPa and Vs in $\mathrm{Km} / \mathrm{sec}$. The results revealed that there is a scattering around the UCS-velocity curves. This can be attributed to the heterogeneity of carbonates formation which are mixed of dolomite intercalated with argillaceous dolomite in addition to conglomerate and locally anhydrite argillaceous (Jeribe Formation), and limestone interrelated with thin argillaceous limestone (Khasib and Mishrif 
formations). In other words, this scattering is related to the complexity of pore rock system. Two correlations (Eqs. 5 and 6) have been constructed in this section, obtaining correlation coefficients (R2) of 0.77 for limestone and (R2) of 0.94 for dolomite, respectively. According to the results of Fig. 4, the results showed that UCS increases linearly with Vs (inversely with sonic travel times).

$$
\begin{gathered}
U C S=4.409 \times V_{S}+0.8045 \\
U C S=4.732 \times V_{S}-1.157
\end{gathered}
$$

\subsubsection{Correlation between (UCS) and P-wave velocity ( $V p$ )}

Fig. 5 presents the relationships between UCS and compressional wave velocities for both limestone (13 samples) and dolomite (4 samples). The relationship between UCS and Vp is expressed in $\mathrm{MPa}$ and $\mathrm{Km} / \mathrm{sec}$, respectively. The results showed a clear scattering around each fit curve. This can be attributed to the different geological setting of limestone and the effect of the diagenetic processes on dolomite which altering the rock framework and pure structures to varying degrees. In addition, this scattering is related to the heterogeneity of formation because of the depositional environments and dolomitization processes.

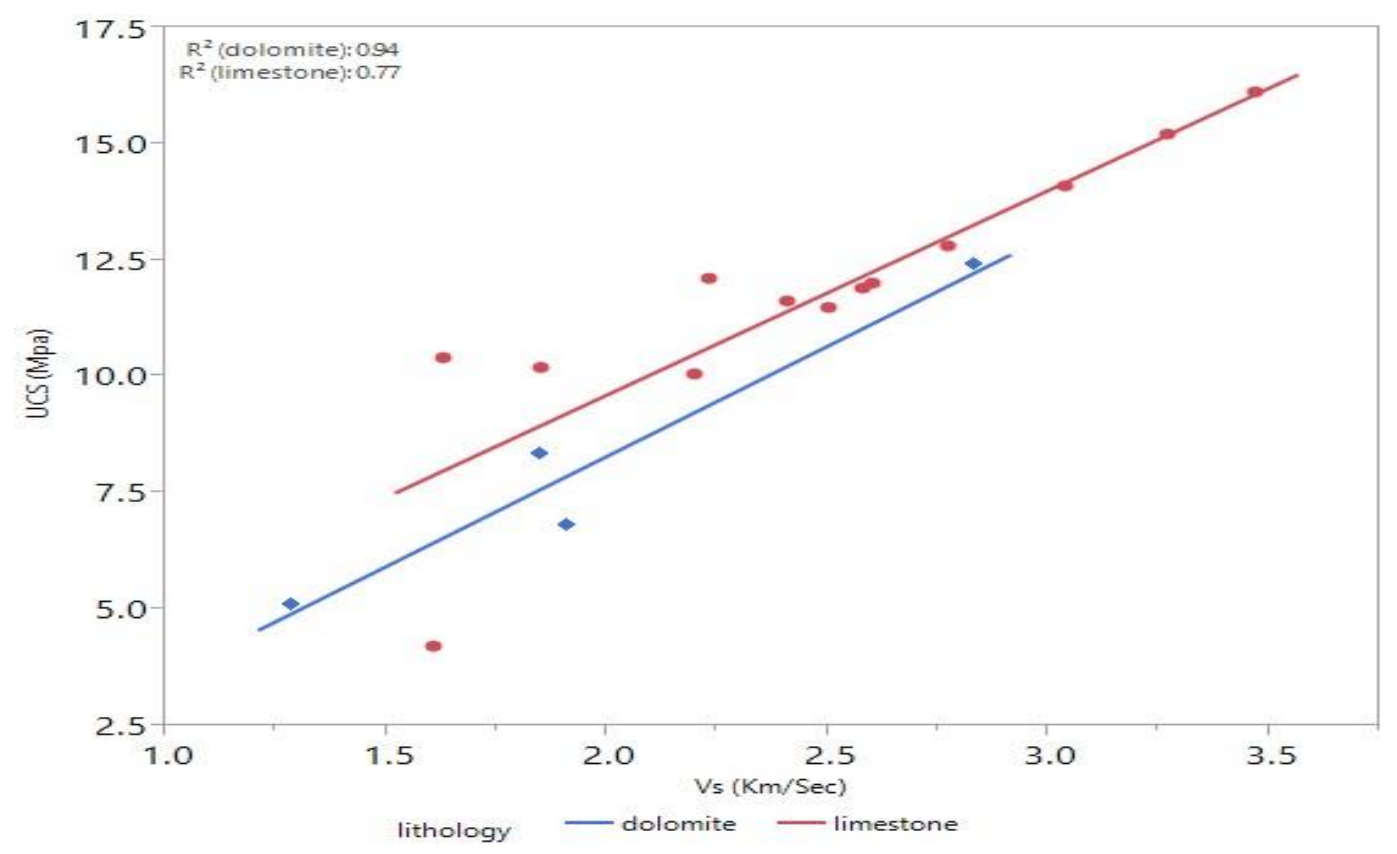

Fig. 4. Relationship between uniaxial compressive strength and S-wave velocity

Two correlations (Eqs. 7 and 8) have been developed to correlate the rock strength with the compressional travel velocity for limestone and dolomite, respectively. Fig. 5 revealed that the rock strength increases with the compressional wave velocity. This supports the evidence that UCS decreases with increasing porosity (increasing sonic travel time or decreasing compressional wave velocity). A correlation coefficient (R2) of 0.65 is for limestone while it is 0.89 for dolomite.

$$
\begin{aligned}
U C S & =2.28 V_{p}+1.939 \\
U C S & =3.304 V_{p}-3.1084
\end{aligned}
$$




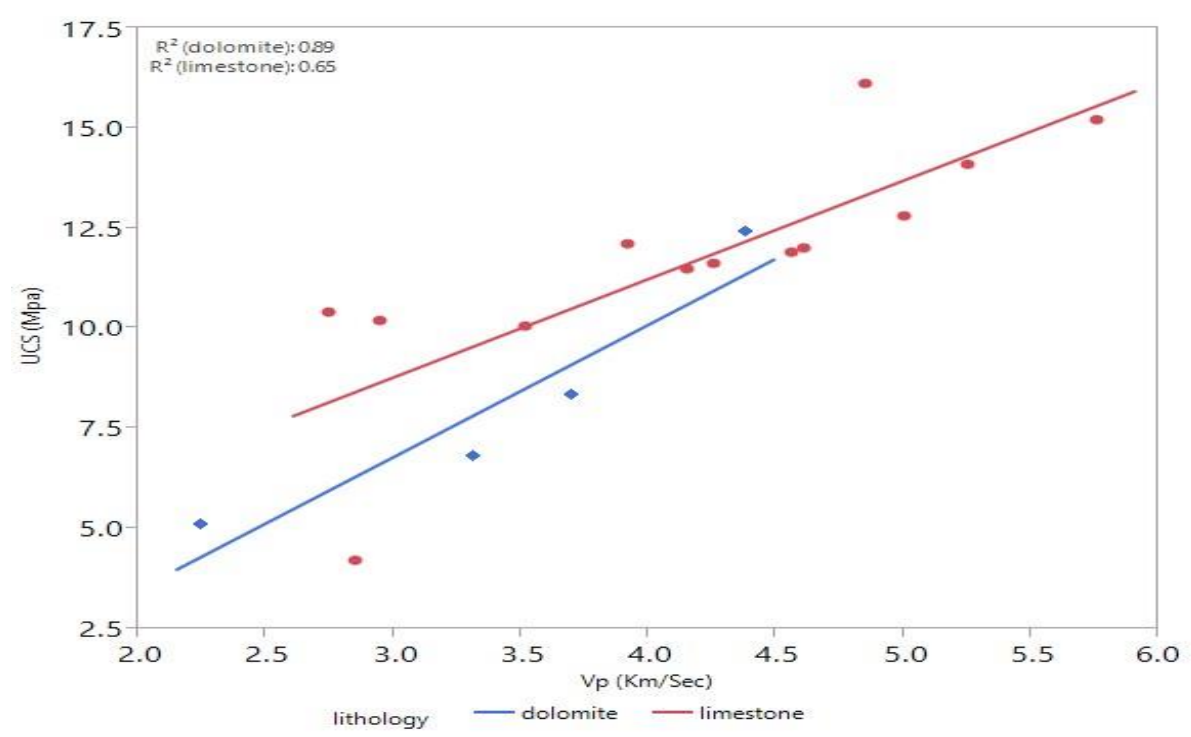

Fig. 5. Relationship between uniaxial compressive strength and P-wave velocity

\subsubsection{Correlation between uniaxial compressive strength and porosity}

The relationship between porosity and UCS values is presented in Fig. 6. the porosity is a controlling factor of rock strength in the basalts that conducted in this study, most of the samples with relatively high porosities tend to be broken at very early stages in the load cycle which exhibit a very low UCS. On the other hand, most of the strong solid samples are associated with extremely low porosity. It also shows a strong correlation of R2 $=0.84$ between UCS and porosity for dolomite and R2 $=0.76$ for limestone according to the Equations 9 for limestone and 10 for dolomite.

$$
\begin{gathered}
U C S=20.35-0.948 \emptyset \\
U C S=14.11-0.5679 \varnothing
\end{gathered}
$$

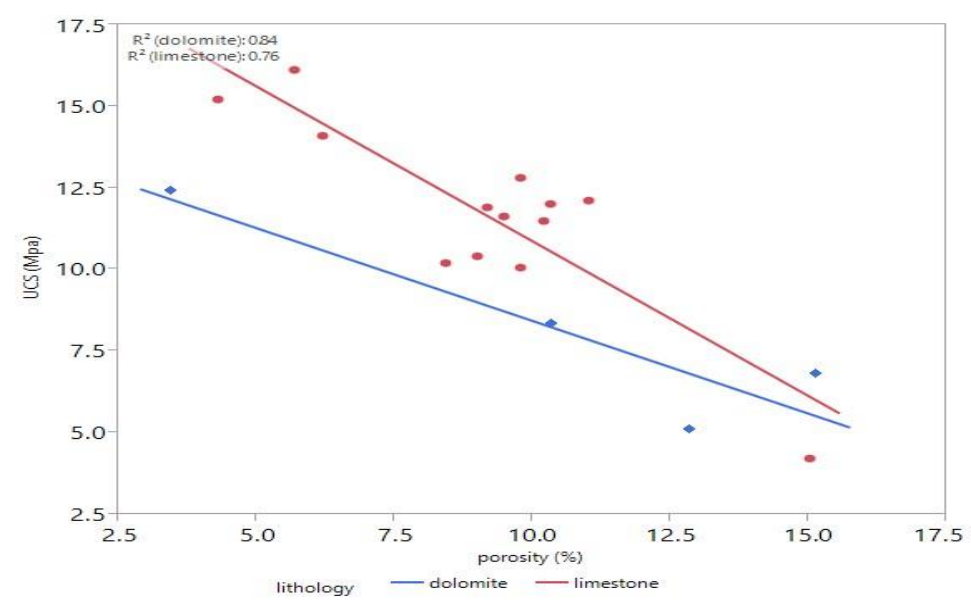

Fig. 6. Uniaxial compressive strength and porosity relationship

\subsubsection{Correlation between uniaxial compressive strength and bulk density \}}

Fig. 7 shows the relationship between bulk density and UCS magnitudes for limestone and dolomite. A best-fit regression curve is obtained, showing a good correlation coefficient for limestone $(\mathrm{R} 2=0.80)$ and a best correlation coefficient for dolomite $(\mathrm{R} 2=99)$. In general, the rock matrix is mainly 
composed of particles that have anisotropic arrangement, resulting a scattering between UCS and bulk density. The developed Equations are respectively 11 and 12 for limestone and dolomite, in which the rock strength (UCS) is linearly increased with the formation density, where UCS in Mpa and bulk density in $\mathrm{gm} / \mathrm{cc}$;

$$
\begin{aligned}
U C S & =16.34 \rho-29.13 \\
U C S & =15.64 \rho-30.52
\end{aligned}
$$

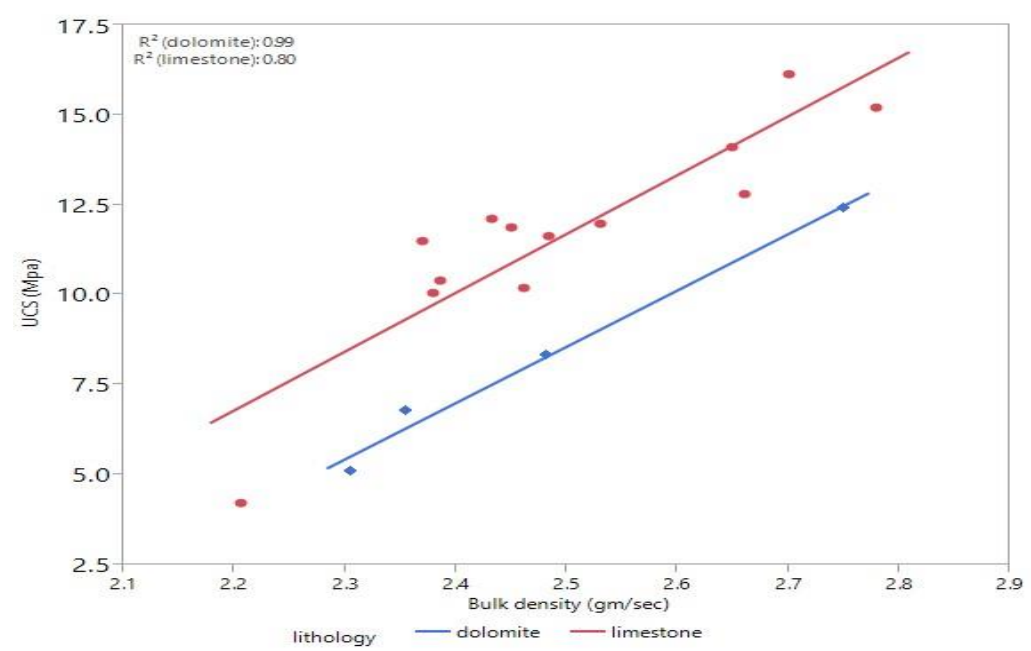

Fig.7. Relationship between UCS and bulk density

\subsubsection{Correlation between compressional wave and shear wave velocity}

The results of the laboratory ultrasonic measured velocities $\mathrm{Vp}$ and $\mathrm{Vs}$ for carbonate (limestone and dolomite) formations are presented in Fig. 8, where both Vs and Vp in Km/sec. Equations 13 and 14 outline the presented fit curve, obtaining equal R 2 of 0.88 for both limestone and dolomite, respectively. There is a scattering around each curve which can be attributed to the heterogeneity of carbonate samples in which the void proportions and pore size distributions within the rock fabric are complex.

$$
\begin{aligned}
& V_{S}=0.5704 V_{P}+0.08569 \\
& V_{S}=0.6729 V_{P}-0.326
\end{aligned}
$$

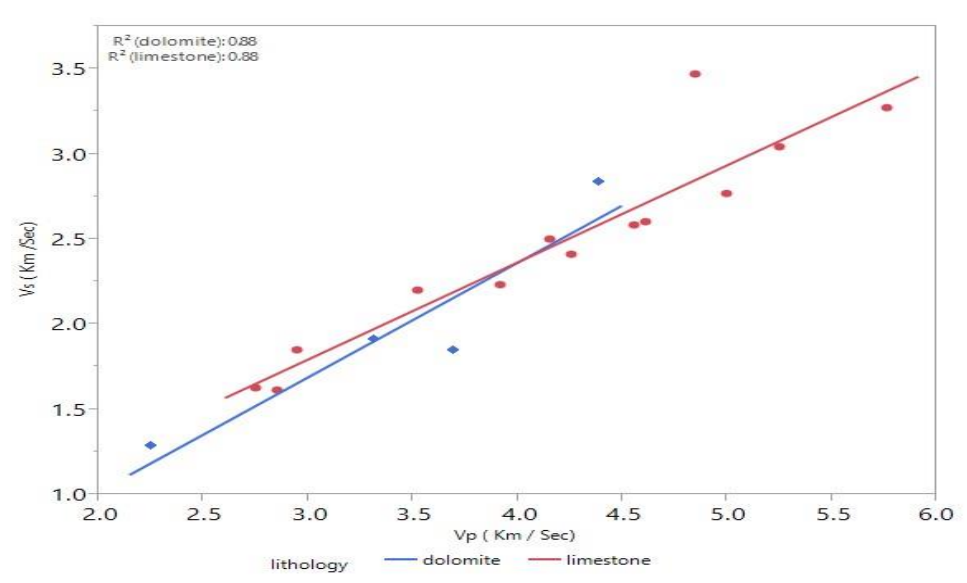

Fig. 8. Relationship between S-wave velocity and P-wave velocity 
To validate our model, we compare the Equation from the core with the log data, as shown in Fig. 9 with R2 $=0.88$ for limestone and R2=0.91 for dolomite.

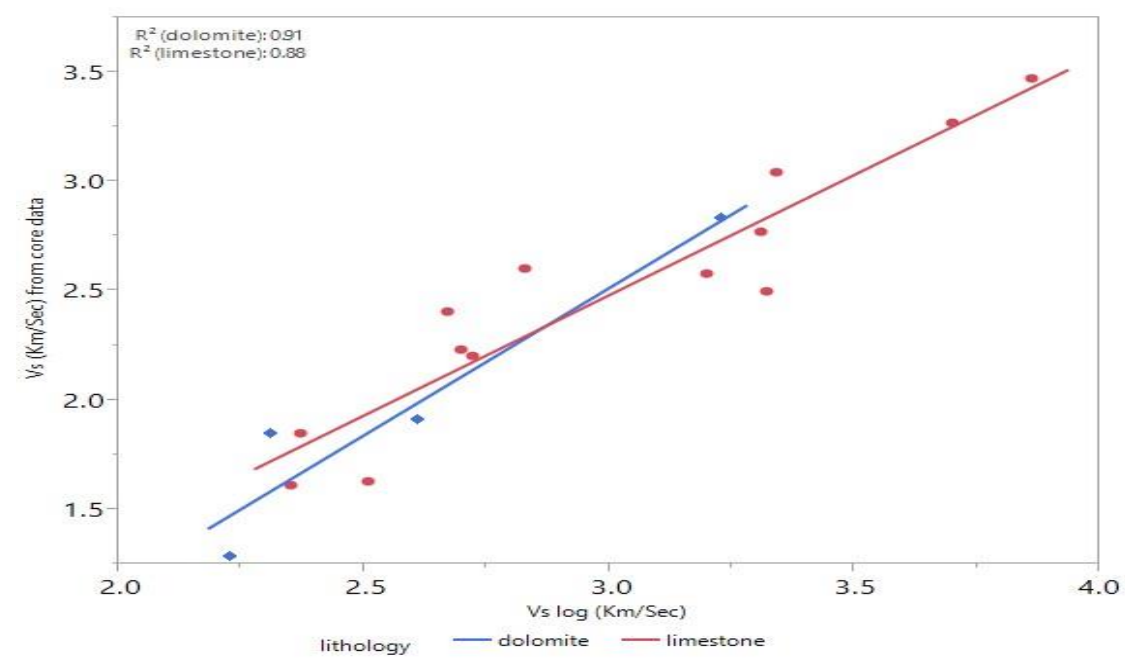

Fig. 9. Plots of predicted Vs. using core data versus measured Vs. from log

\subsubsection{Correlation between $S$-wave velocity and bulk density}

Fig. 10 shows the relationship between S-wave velocity and bulk density of carbonate rocks. there are good relationships between $\mathrm{S}$-wave velocity and bulk density with $\mathrm{R} 2=0.76$ for limestone and $\mathrm{R} 2=88$ for dolomite. The scatter in the data can be attributed to sample heterogeneities, matrix is mainly composed of particles. According to Equation 15 for limestone and Equation 16 for dolomite, S-wave velocity increases linearly with increasing bulk density. the equations of the relation are:

$$
\begin{aligned}
& V s=3.175 \times P-5.46 \\
& V s=3.033 \times P-5.532
\end{aligned}
$$

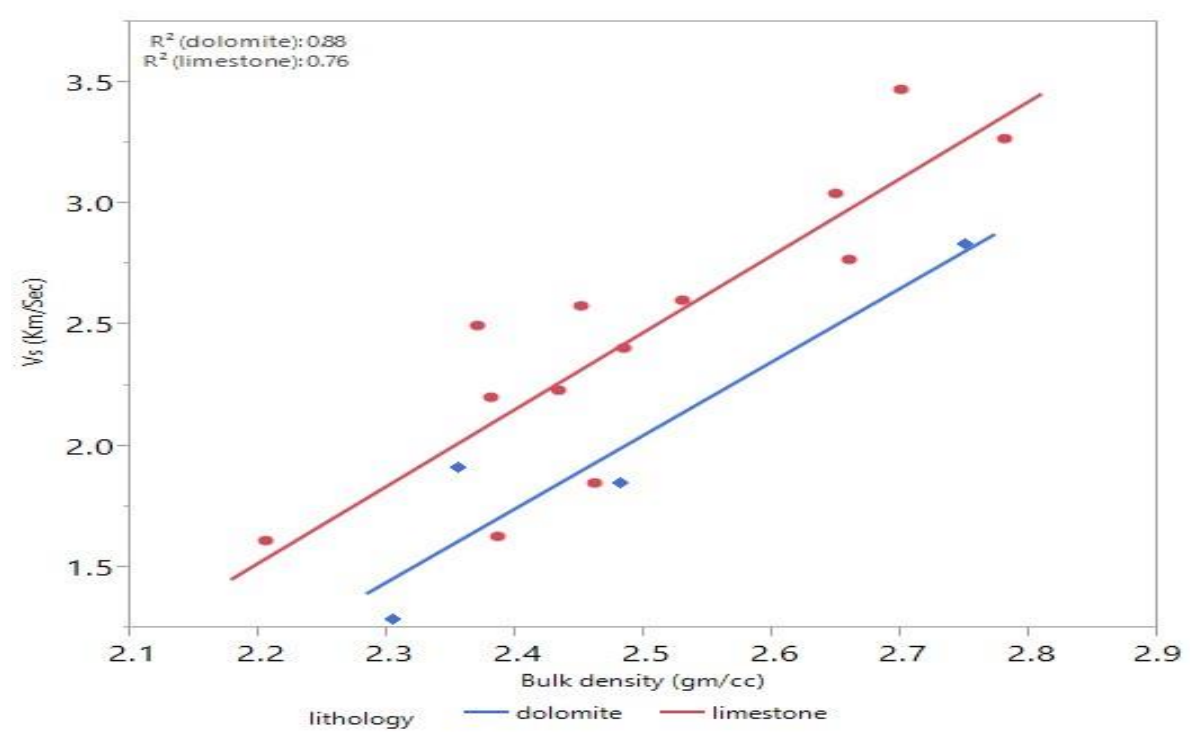

Fig. 10. Relationship between vs. and bulk density 


\subsubsection{Correlation between P-wave velocity and bulk density}

Fig. 11 shows the relationship between P-wave velocity and bulk density of limestone and dolomite. The results support good relationships between P-wave velocity and bulk density with R2 $=0.73$ for limestone and $\mathrm{R} 2=0.81$ for dolomite, Where $\mathrm{Vp}$ in $\mathrm{km} / \mathrm{sec}$ and bulk density in $\mathrm{gm} / \mathrm{cc}$. The scatter of even the mean values around the regression lines is due to the complex depositional environments and digenetic processes of carbonate rocks. According to Equation 17 for limestone and Equation 18 dolomite P-wave velocity increases linearly with increasing bulk density. the equations of the relation are:

$$
\begin{aligned}
& V p=5.059 \times P-8.547 \\
& V p=4.073 \times P-6.573
\end{aligned}
$$

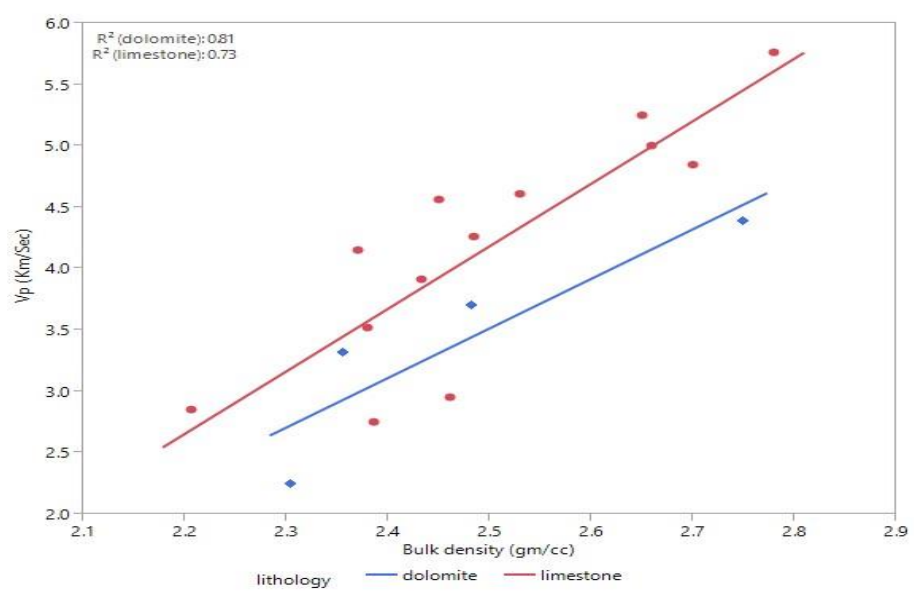

Fig. 11. Relationship between P-velocity and bulk density

\subsubsection{Correlation between young modulus and shear wave velocity}

The regression curves between Young's modulus on S-wave velocity of carbonate rocks are shown in Fig. 12 and presented by Equation 19 for limestone and Equation 20 for dolomite. Determination coefficients $\left(\mathrm{R}^{2}\right)$ are 0.97 and 0.98 for limestone and dolomite, respectively. These direct correlations mean that increasing the rock Young's modulus causes an increasing in S-wave velocity.

$$
\begin{aligned}
& E_{S}=26.77 V_{s}-26.69 \\
& E_{S}=29.62 V_{s}-34.39
\end{aligned}
$$

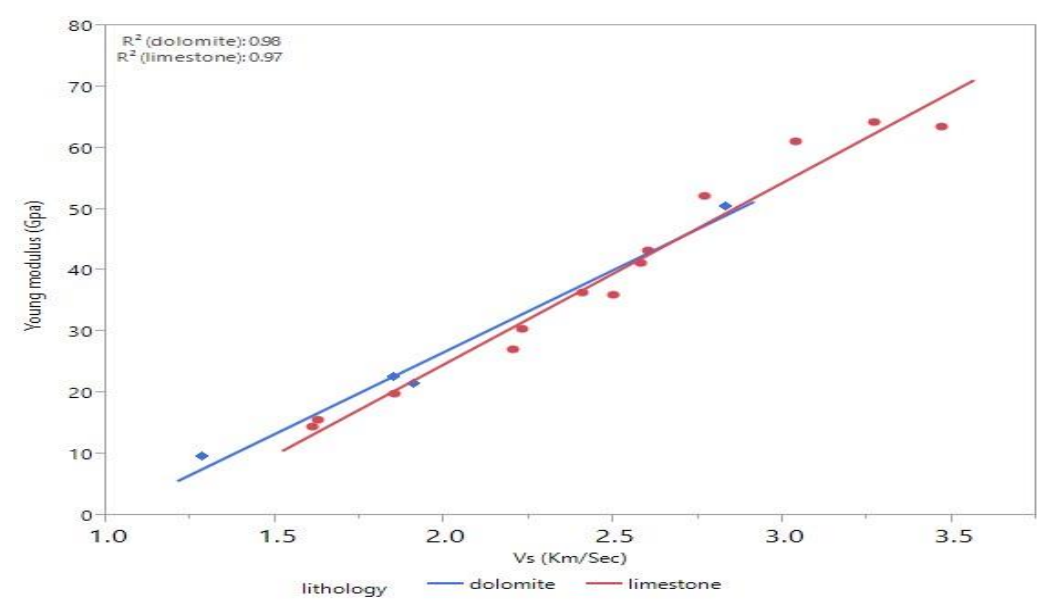

Fig. 12. Relationship between young modulus and S-wave velocity 


\subsubsection{Correlation between young modulus and P-wave velocity}

The regression lines of young modulus on the P-wave velocity of carbonate rock for the combined data are shown in Fig. 13 and presenting by equation 21 for limestone and Equation 22 for dolomite with determination coefficients of 0.93 and 0.84 , respectively. The points are scattered uniformly about the diagonal line rock since the strength parameters are a function of physical, textural, and mineralogical properties of rock. Based on these correlations, an increasing in P-wave velocity (decreasing sonic travel time or porosity) increases the rock stiffness (increasing Young's modulus).

$$
\begin{aligned}
& E S=17.67 \mathrm{~V}_{P}-35.1 \\
& E S=17.72 \mathrm{~V}_{P}-34.41
\end{aligned}
$$

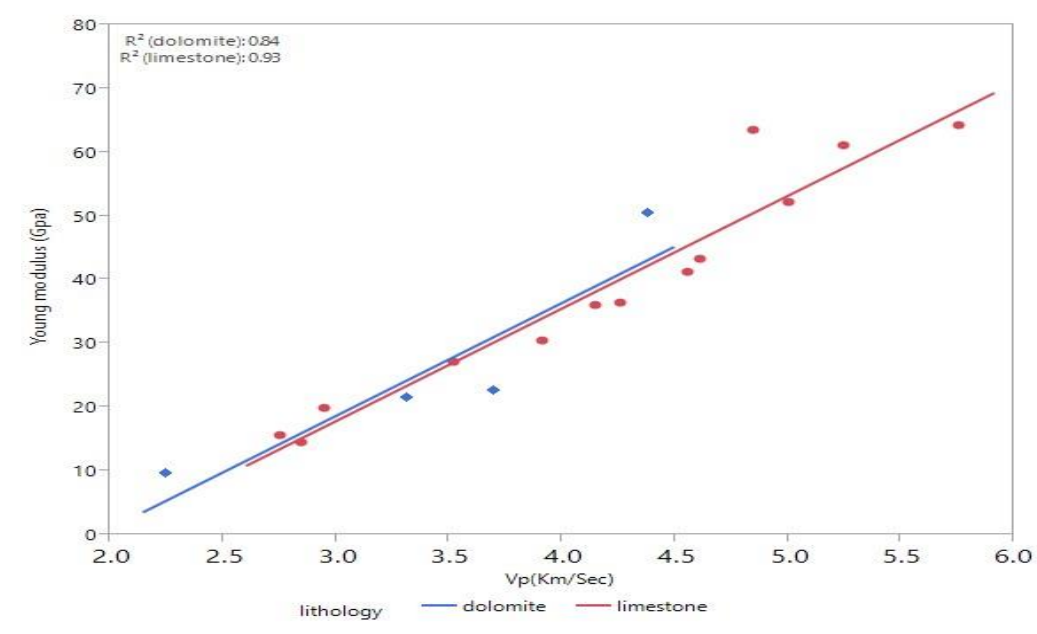

Fig. 13: Relationship between young modulus and P-wave velocity

\subsection{Comparison between new correlations with the previous Empirical correlations}

In this section, the developed correlations have been compared with some previous correlations in Table 1. The new correlation gives an excellent matching with Ameen (2009) and Castagna (1993) correlation but relatively less matching with Al-Kattan (2015) correlation for limestone formation.

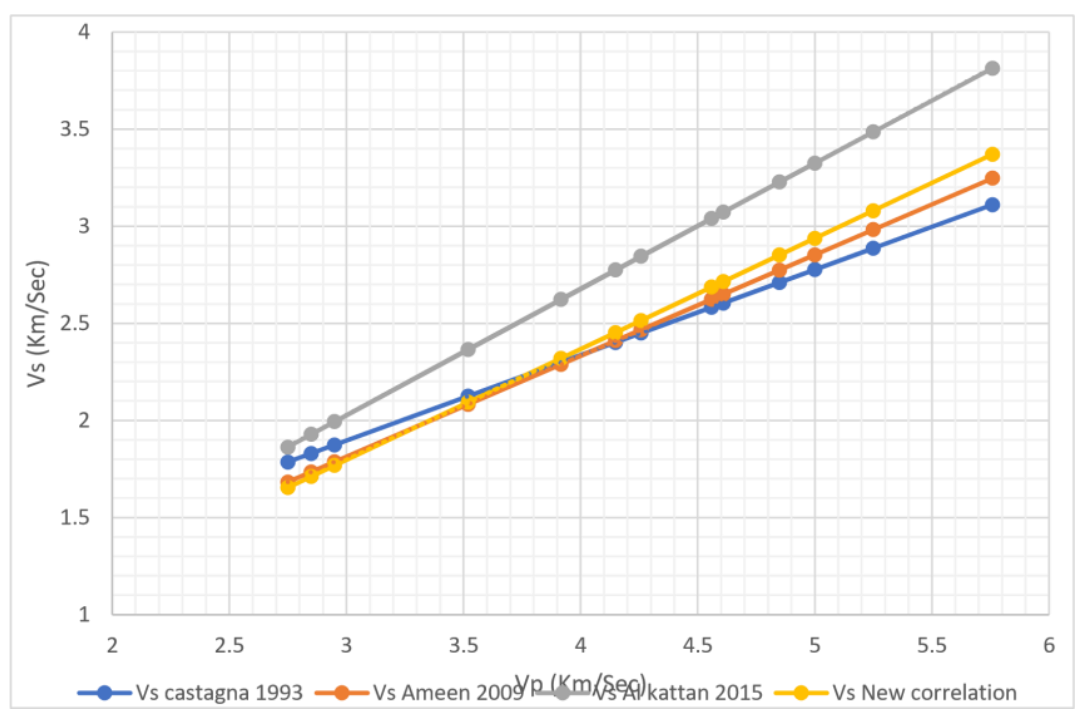

Fig. 14. Comparison between Equation 13 and other empirical relation to predict Vs. for limestone rock formation from core data 
the new correlation is compared with the other correlations for dolomite formation. The results show an excellent matching between the developed correlation, Ameen (2009) and Castagna (1993) correlations but it has a little difference with Al-Kattan correlation (2015), (Fig. 15).

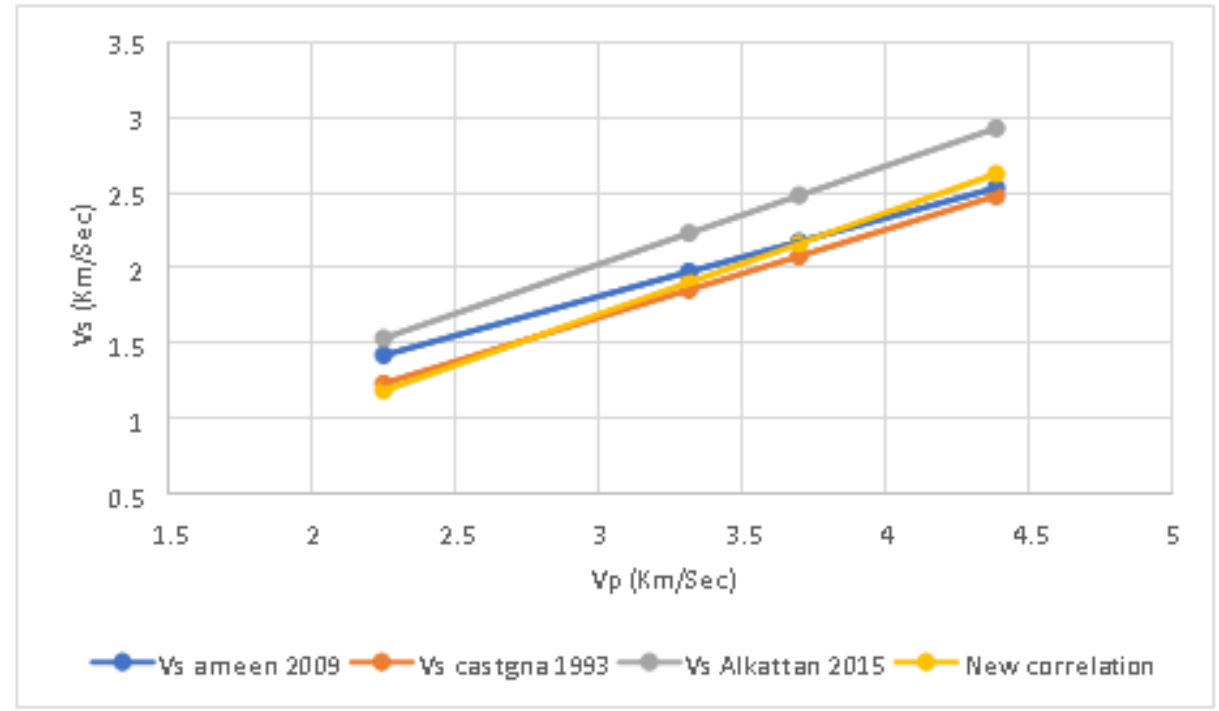

Fig.15. Comparison between equation 14 and other empirical relation to predict Vs. for dolomite rock formation from core data

The new correlation is matched the Ameen (2009) and Castagna (1993) correlations but less relative matching with the Kattan correlation (2015). The new correlation gives an excellent matching with Ameen (2009) and Castagna (1993) correlations but have some differences with Kattan correlation (2015) (Fig. 17).

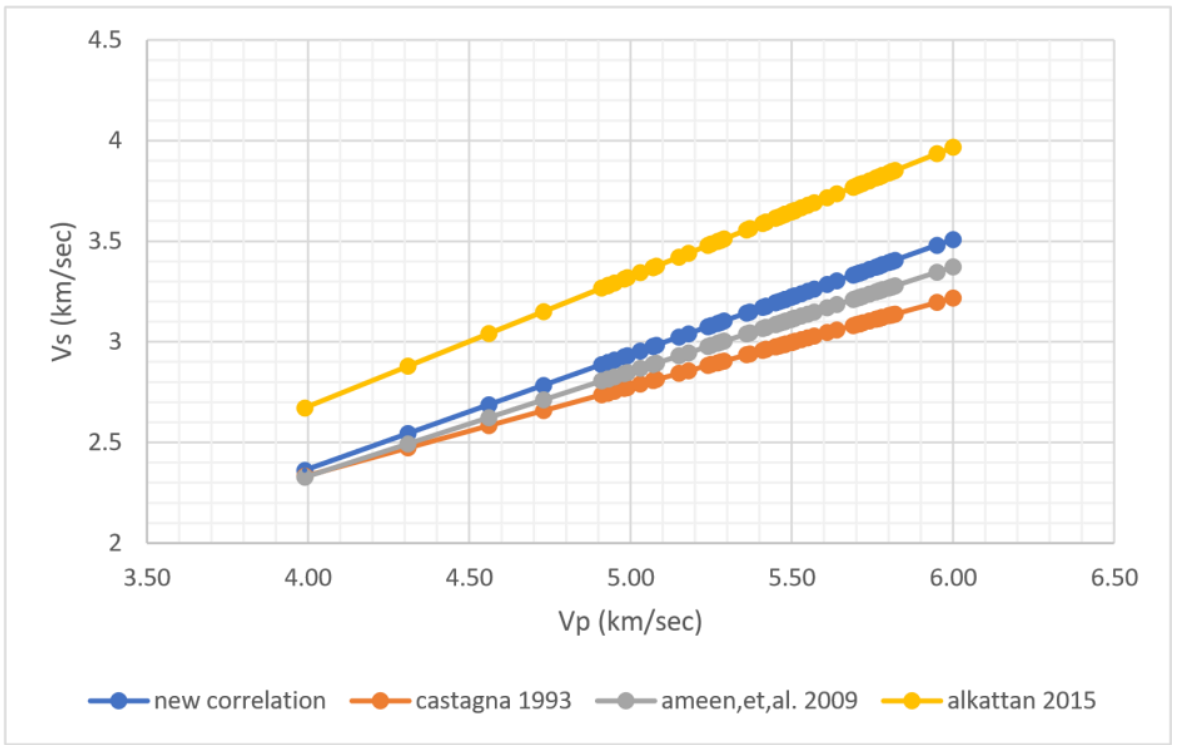

Fig.16. Comparison between equation 13 and other empirical relation to predict Vs. for limestone rock in the Khasib Formation from log data 


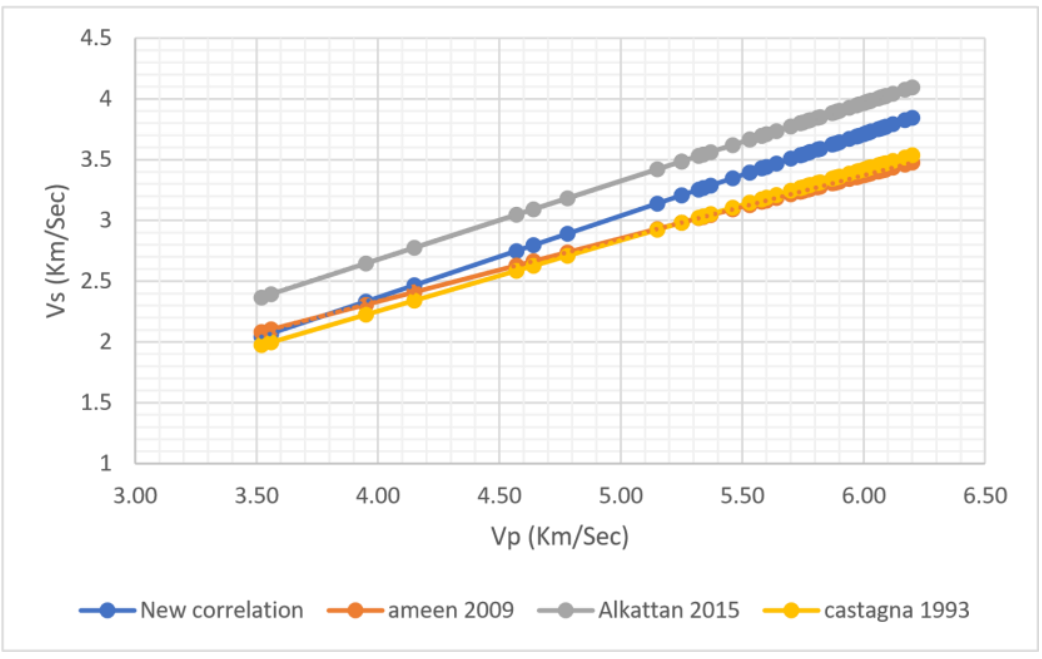

Fig. 17. Comparison between equation 14 and other empirical relation to predict Vs. for dolomite rock formation from $\log$ data

\section{Conclusions}

This study presents a set of correlations to estimate the rock mechanical and elastic properties based on lab experimental works using the multiple regression analysis technique. A field case (FAUQI oil field), located in southeast Iraq, was conducted to correlate the rock mechanical with petrophysical properties. The greatest difference between this study and previous studies is that there are no local studies to estimate the rock mechanical properties in this field of interest. The conclusion of this study can be summarized in the following points:

- Petrophysical rock properties including porosity, compressional shear aves, and bulk density are consistent indexes to estimate the rock mechanical properties.

- The results are more conservative in estimating UCS rather than using previous correlations.

- The results of Vs and Vp are well matched well log data when the core plugs are saturated with diesel oil than when the core plugs are dried.

- The presented correlations can be used to estimate UCS, Vs, and Vp from well log data if the core samples are limited or not available, which is a cost effective correlation.

- Even though all of Vs correlations (previous and developed) show a good match with well log data, their prediction ability is different. For example, Castagna and Ameen correlations show a closely match with the developed correlations while AlKattan correlation showed an overestimation of Vs magnitudes.

- The developed correlations in this study can be locally used with high performance capacity, but it requires a calibration when it will be used in another field of interest.

\section{Nomenclature}

UCS: uniaxial compressive strength

Vp: compressional wave

Vs: shear wave

Es: young modulus

UV: ultrasonic velocities

ASTM: American Society for Testing and Materials

ISRM International Society for Rock Mechanics 


\section{Acknowledgements}

The authors are very grateful to the Editor in chief Prof. Dr. Salih M. Awadh, the Secretary of Journal Mr. Samir R. Hijab. and the Technical Editors for their great efforts and valuable comments.

\section{References}

Abdul Majeed, R. K., Alhaleem, A. A., 2020. Estimation of shear wave velocity from wireline logs data for Amara oil field, Mishrif Formation, southern Iraq, Iraqi Geological Journal, 53(1A), 36-47.

Al-Kattan, W., Al-Ameri, N.J., 2015. Estimation of the rock mechanical properties using conventional log data in North Rumaila Field. Iraqi Journal of Chemical and Petroleum Engineering. 13 (4), 27-33.

Ameen, M. S., Smart, B. G., Somerville, J. M., Hammilton, S., Naji, N. A., 2009. Predicting rock mechanical properties of carbonates from wireline logs; A case study; Arab-D reservoir, Ghawar field, Saudi Arabia. Marine and Petroleum Geology, 26(4), 430-444.

ASTM, 1986. Standard Test Method of Unconfined Compressive Strength of Intact Rock Core Specimens. ASTM Publication.

Bjorlykke, K., Hoeg, K., 1997. Effects of burial diagenesis on stresses, compaction, and fluid flow in sedimentary basins. Marine and Petroleum Geology 14, 267-276.

Castagna, J. P., Batzle, M. L., Kan, T. K., 1993. Rock physics - The link between rock properties and AVO response. In: Offset-dependent reflectivity-theory and practice of AVO analysis: Castagna, J.P., and Backus, M. (Eds.). Society of Exploration Geophysicists, 135-171.

Chang, C., Zoback, M.D., Khaksar, A., 2006.Empirical relations between rock strength and physical properties in sedimentary rocks. Journal of Petroleum Science and Engineering ,51(3), 223-237.

Hadi, F. A., and Nygaard, R., 2018. Shear wave prediction in carbonate reservoirs can Artificial nearal Network outperform regression Analysis? In 52 ${ }^{\text {nd }}$ US Rock Mechanics, Geomechanics Symposium. American Rock Mechanics Association.

ISRM, 2007. The Complete ISRM Suggested Methods for Rock Characterization. Testing and Monitoring: 19742006. International Society for Rock Mechanics, Commission on Testing Methods.

Karamia, M., Abrah, B., Dayani, S., Faramarzi, L., Nik, M. G., 2012, January. Empirical correlations between static and dynamic properties of intact rock. In ISRM Regional Symposium-7th Asian Rock Mechanics Symposium. International Society for Rock Mechanics and Rock Engineering.

Khandelwal, M. S., Singh, T.N., 2009. Correlation static properties of rock with P-wave velocity international Jornal of Coal Geology,49 (1), 55-60.

Meehan, N.D., 1994. Roch mechanics issues in petroleum engineering. In: Nelson, P.P., Lauback, S.E. (Eds.), Rock Mechanics. Balkema, Rotterdam.

Militzer, H., Stoll, R., 1973. Einige Beiträigeder Geophysi kzurprimädatenerfassung im Bergbau: NeueBergbautechnik.Leipzig, 3, 21-25.

Raaen, A. M., Hovem, K. A., Joranson, H., and Fjaer, E., 1996. FORMEL: A Step Forward in Strength Logging. In Proceedings of the SPE Annual Technical Conference and Exhibition, Denver, Colorado.

Rabbani, E., Sharif, F., Koolivand Salooki, M., Moradzadeh, A., 2012. Application of neural network technique for prediction of uniaxial compressive strength using reservoir formation properties. International Journal Rock Mechanics and Mining Society, 56, 100-111

Tawfeeq, Y. J., Al-Sudani, J. A., 2020. Digital rock analysis: an alternative method to predict petrophysical properties, case study from Mishrif Formation. Iraqi Geological Journal, 53(2C), 34-55.

Smorodinov, M. I., Motovilov, E. A.,Volkov, V. A., 1970. Determination of correlation relationships between strength and some physical characteristics of rocks, Proceeding of the Second Congress of the International Society for Rock Mechanics, Beograd, 21-26.

Yagiz, S., 2011. P-wave velocity test for assessment of geotechnical properties of some rock materials. Bulletin Material Society, 34 (4), 947-953. 